\title{
Evaluation on Thyroid Nodule Malignancy by Ultrasound Findings: A Teaching Hospital Based Study
}

\author{
Kiran Kumar Neelapu ${ }^{1}$ \\ ${ }^{1}$ Assistant Professor, Department of Radiology, Nimra Institute of Medical Sciences, Nimra Nagar, Ibrahimpatnam, Jupudi, Vijayawada, krishna District, \\ Andhra Pradesh.
}

\section{Abstract}

Background: Thyroid nodule is a common clinical problem and the incidence of thyroid nodules has increased with the recently increasing use of thyroid ultrasonography in India. Subjects and Methods: The study included total 186 cases among which 184 were females and 02 were males. Patients with diagnosed thyroid nodules of more than $1 \mathrm{~cm}$ and who underwent ultrasonography were included.Results: From all nodules, $22.65 \%$ ) were single and $76.34 \%$ were multiple nodules; 60 nodules $(32.25 \%)$ were solid and $126(67.74 \%)$ cystic. Concerning echogenicity, 44 nodules (23.65\%) were Hypo-echo and 35 nodules (18.8\%) Hyper-echo. 179 nodules (96.23\%) had a regular edge. 65 nodules $(34.9 \%)$ had without Halo. 140 nodules $(75.2 \%)$ were larger than $15 \mathrm{~mm}$. According to histopathology results, the benign nodules were $88.7 \%$ and malignant cases were $11.3 \%$.Conclusion: Based on the result of this study, thyroid nodule size must not be considered as a criterion for malignancy and thyroid nodules of any size must be suspected as malignant. Important criteria for malignancy include irregular edges, being Solid hypoechogenicity and being a single nodule respectively.

Keywords: Thyroid nodules, Ultrasound, Fine-Needle Aspiration, Benign and Malignancy.

Corresponding Author: Dr. Kiran Kumar Neelapu, Assistant Professor, Department of Radiology, Nimra Institute of Medical Sciences, Nimra Nagar, Ibrahimpatnam, Jupudi, Vijayawada, krishna District, Andhra Pradesh.

Received: March 2018

Accepted: June 2018

\section{Introduction}

A thyroid nodule is a discrete lesion within the normal thyroid. Thyroid nodules are very common findings in the adult population, especially in women. ${ }^{[1]}$ According to a projection from various studies on thyroid disease, it has been estimated that about 42 million people in India suffer from thyroid diseases. ${ }^{[2]}$ Thyroid nodules are common, their prevalence being chiefly dependent on the identification technique. The estimated prevalence by palpation alone ranges from $4 \%$ to $7 \%$, up to $67 \%$ by ultrasound, and fifty percent at autopsy with a noticeably higher incidence in iodinedeficient provinces. ${ }^{[3-5]}$ Thyroid nodules have been defined by the American Thyroid Association (ATA) as "discrete lesions within the thyroid gland, radiologically distinct from surrounding thyroid parenchyma. ${ }^{[6]}$ "Thyroid nodules are clinically important for several reasons. They may cause thyroid dysfunction and, rarely, compressive symptoms, but they are primarily important because of the need to exclude thyroid cancer. Therefore, it should be distinguishable from the adjacent thyroid tissue either on palpation or radiologically. Thyroid nodules are 4 times more common in women than men and their frequency increases with age and low iodine intake. ${ }^{[7]}$ Indeed, as compared with FNA, thyroid US has been the crucial diagnosis method of thyroid nodules as the advantage of being a noninvasive procedure and giving immediate information. Yet the clinical importance of thyroid nodules lies in the detection of malignancy, the great majority of nodules are benign, less than $5 \%$ of them being malignant. ${ }^{[8,9]}$ For the small sample sizes many studies are limited to analysis the association between the ultrasound imaging characteristics of thyroid nodules and the risk of thyroid cancer. ${ }^{[10-12]}$ This ascertainment bias will overestimate the risk of cancer associated with the accuracy of ultrasound imaging. This study was aimed to determine the ultrasound imaging findings of thyroid nodules in patients and correlate it with clinical records to develop a standardized diagnosis sys $\neg$ tem for interpreting thyroid ultrasound imaging.

\section{Subjects and Methods}

This present study was carried out in the Department of Radiology, Nimra Institute of Medical Sciences, Nimra Nagar, Ibrahimpatnam, Jupudi, Vijayawada, krishna District, Andhra Pradesh, India during the period from 2015 to 2016. The study included total 186 cases among which 184 were females and 02 were males. Patients with diagnosed thyroid nodules of more than $1 \mathrm{~cm}$ and who underwent ultrasonography were included. Ultrasound 


\section{Neelapu; Evaluation an Thyroid Nodule Malignancy by Ultrousaund Findings}

Examination Technique: A detailed examination of the neck for any cervical lymphadenopathy should always be carried out in the ultrasound examination of thyroid since metastatic cervical lymph nodes are commonly seen in thyroid cancers and may have an effect on the surgical management and prognosis of patients. In these patients, high frequency 7.510.0 $\mathrm{MHz}$ probe was used for Ultrasound examination of a thyroid nodule. It includes diameter, echogenicity (Hyper, Hypo, Iso and An Echo), composition (Cystic, Solid, Mixed), microcalcifications (Presence and Absence), Borders (Irregular and Regular) and Halo (Presence and Absence). From Lew et al. guidelines ultrasound of nodule margins, suggestive of malignancy guidelines was adopted.13 A fine needle aspiration (FNA) biopsy was recommended to the referring physician is required. ${ }^{[14,15]}$ The study was approved by the ethical Committee of Nimra Institute of Medical Sciences. All participants provided informed written consent to participate in it.

\section{Results \& Discussion}

In this study 186 patients were examined; 184 patients $(98.9 \%)$ were females and the $(1.07 \%)$ were males. Their mean age was $34.6 \pm 24.02$ years. None of the patients had a history of neck irradiation in childhood. Only one of the patients with benign nodule had the history of papillary carcinoma among family members (sister of the patient). From all nodules, $22.65 \%$ ) were single and $76.34 \%$ were multiple nodules; 60 nodules $(32.25 \%)$ were solid and 126 $(67.74 \%)$ cystic. Concerning echogenicity, 44 nodules (23.65\%) were Hypo-echo and 35 nodules (18.8\%) Hyper- echo. 179 nodules $(96.23 \%)$ had a regular edge. 65 nodules (34.9\%) had without Halo. 140 nodules $(75.2 \%)$ were larger than $15 \mathrm{~mm}$. According to histopathology results, the benign nodules were $88.7 \%$ and malignant cases were $11.3 \%$. Summary of FNAC and Histopathology given in [Table2]. Prehand information of nature of disease alters the treatment options greatly. In thyroid, benign nodules require partial thyroidectomy or lobectomy, whereas malignant disease demand extensive surgery, i.e., total thyroidectomy, neck dissection followed by radio iodine ablation and lifetime dependency on thyroxine supplement. In thyroid disease, this benefit of prehand knowledge of pathology is granted by FNAC which is a well establish technique for preoperative assessment of thyroid nodules. ${ }^{[16]}$ The FNAC is cost-effective, less traumatic, less invasive, and easily performed procedure. ${ }^{[17]}$ FNAC is a useful tool in the diagnosis in thyroid nodules if a suspicion of cancer exists. It has reduced the need of imaging and surgery and increased the yield of cancer in patients who come for surgery. ${ }^{[18]}$ After surgery and pathology, 21 cases (10.2\%) were reported malignant while 19 cases (9.1\%) were confirmed malignant in FNAC. All of these nodes were papillary thyroid carcinoma. There was no significant relationship between sex and malignancy $(p=1)$. Most of malignant nodules were single nodules $(\mathrm{p}=0.0001)$ and solid $(p<0.0001)$. Most malignancies had irregular edges $(p=0.15)$ and calcifications $(p=0.02)$. There was no significant relationship between malignancy and nodule size of larger than $15 \mathrm{~mm} \quad(\mathrm{p}=0.395)$. Compared with surgery, FNA sensitivity and specificity were calculated as $85.7 \%$ and $99.4 \%$, respectively.

\begin{tabular}{|c|c|c|c|c|c|}
\hline $\begin{array}{c}\text { Individual or group } \\
\text { features }\end{array}$ & & benign $($ Sum=167) & malignant (Sum=19) & $\begin{array}{c}\text { Odd ratios } \\
\text { (Confidence interval of 95\%) }\end{array}$ & P-value \\
\hline \multirow[t]{2}{*}{ Sex } & Male & 2 & 0 & & \multirow[t]{2}{*}{1} \\
\hline & Female & 165 & 19 & & \\
\hline \multirow[t]{4}{*}{ Age range } & $<15$ & 1 & 2 & & \\
\hline & $15-35$ & 22 & 3 & & \\
\hline & $35-55$ & 64 & 6 & & \\
\hline & $>55$ & 80 & 8 & & \\
\hline \multirow{2}{*}{ No. of nodules } & Single nodule & 32 & 12 & \multirow{2}{*}{$7.23\{2.63-19.83\}$} & \multirow{2}{*}{$0.0001 *$} \\
\hline & Multi nodule & 135 & 7 & & \\
\hline \multirow[t]{3}{*}{ TSH level } & Normal & 124 & 10 & & \\
\hline & Hypothyroidism & 16 & 5 & & \\
\hline & Hyperthyroidism & 27 & 4 & & \\
\hline \multirow{2}{*}{ Nodule type } & Solid & 43 & 17 & \multirow{2}{*}{$24.51\{5.43-110.48\}$} & \multirow[t]{2}{*}{$<0.0001^{*}$} \\
\hline & Cystic and mixed & 124 & 2 & & \\
\hline \multirow[t]{3}{*}{ Echogenicity } & Нypo & 36 & 8 & & \\
\hline & Hyper & 33 & 2 & & \\
\hline & iso & 98 & 9 & & \\
\hline \multirow[t]{2}{*}{ Margins } & irregular & 5 & 2 & \multirow[t]{2}{*}{$3.81\{0.686-21.16\}$} & \multirow[t]{2}{*}{0.152} \\
\hline & Regular & 162 & 17 & & \\
\hline \multirow[t]{2}{*}{ Halo } & Without halo & 47 & 18 & \multirow[t]{2}{*}{$45.95\{5.96-354.06\}$} & \multirow[t]{2}{*}{$<0.0001^{*}$} \\
\hline & With halo & 120 & 1 & & \\
\hline \multirow[t]{2}{*}{ Nodule size } & Larger than $15 \mathrm{~mm}$ & 126 & 14 & \multirow[t]{2}{*}{$0.911\{0.30-2.68\}$} & \multirow[t]{2}{*}{1} \\
\hline & Smaller than $15 \mathrm{~mm}$ & 41 & 5 & & \\
\hline \multirow[t]{2}{*}{ Calcification } & With calcification & 37 & 9 & \multirow[t]{2}{*}{$3.16\{1.19-8.35\}$} & \multirow[t]{2}{*}{$0.02 *$} \\
\hline & Without calcification & 130 & 10 & & \\
\hline
\end{tabular}

Fisher test was used for comparison. (* The difference was statistically significant.)

In this study the prevalence of malignant nodules was 


\section{Neelapu; Evaluation an Thyraid Nadule Malignancy by Ultrasaund Findings}

specificity for diagnosis of nodules were $85.7 \%$ and $99.4 \%$, respectively. Being a single nodule, being solid, being hypoecho, having irregular edges or calcification were the appropriate characteristics for differentiating malignant from benign nodules while the nodule size did not have appropriate differential value. In other studies, the prevalence of malignancy has been different. From all, 3.6\% to $9.9 \%$ of all thyroid nodules have been reported malignant. ${ }^{[19-22]}$ In my study the prevalence of malignancy was about the approximately same. In most studies, age and sex were not associated with malignancy. ${ }^{[23-25]}$ In addition in most studies the sensitivity and specificity of FNA have been better than surgery; hence using FNA together with sonography can be very efficient even for small nodules. ${ }^{[23,26]}$ FNA had high sensitivity and specificity in our study.

\begin{tabular}{l}
\hline Table 2: Nature of thyroid nodules in FNAC and histopathology \\
\begin{tabular}{|c|c|c|c|c|}
\hline $\begin{array}{c}\text { Thyroid } \\
\text { nodules }\end{array}$ & FNAC & $\begin{array}{l}\text { Percentage } \\
(\boldsymbol{\%})\end{array}$ & Histopathology & $\begin{array}{l}\text { Percentage } \\
(\boldsymbol{\%})\end{array}$ \\
\hline Benign & 167 & 89.8 & 165 & 88.7 \\
\hline Malignant & 19 & 10.2 & 21 & 11.3 \\
\hline
\end{tabular}
\end{tabular}

Table 3: Summary of FNAC and Histopathology

\begin{tabular}{|c|c|c|}
\hline \multirow{2}{*}{ Table 3: Summary of FNAC Findings } & \multicolumn{2}{|c|}{ Histopathology Findings } \\
\cline { 2 - 3 } & Malignancy Present & Malignancy Absent \\
\hline Malignancy & $18(10.8 \%)$ & $1(1.07 \%)$ \\
Positive & (True Positive) & (False Positive) \\
\hline Malignancy & $3(1.07 \%)$ & $164(88.7 \%)$ \\
Negative & (False Negative) & (True Negative) \\
\hline
\end{tabular}

Some studies have been conducted to assess sonography parameters in differentiating malignant from benign thyroid nodules; the results have been inconsistent, and it is still controversial. ${ }^{[19,27]}$ In a study in US, sonographic features failed to differentiate benign and malignant thyroid nodules and fineneedle aspiration was recommended for all cases. ${ }^{[19]}$ In some studies sonography had been unable to differentiate malignant and benign cases and FNA is recommended for all thyroid nodules regardless palpability. ${ }^{[2,29]}$ In a study, none of sonography characteristics, except calcification, was able to differentiate benign and malignant thyroid nodes. ${ }^{[19]}$ However, there are studies in favor of the usefulness of sonography markers in differentiating malignant from benign nodules. In a study, having a single nodule, irregular edges, and micro-calcification increased the chance of malignancy 3.6, 5.4 and 39 times, respectively. ${ }^{[23]}$ In Taneri et al study30, having multi nodules was associated with malignancy, while in Ugurlu et al, ${ }^{[23]}$ study having a single nodule or two nodules increased the chance of malignancy and in Cappelli et al, ${ }^{[35]}$ study being solid and hypo-echo were associated with malignancy. However in another study hypoechoechogenicity was not associated with malignancy. ${ }^{[23]}$ Unclear edges, irregular shape, being solid and hypoechoechogenicity can increase the chance of malignancy. ${ }^{[27,31,32]}$ In another study, a greater percentage of malignant nodules had irregular edges and hypoechoechogenicity. ${ }^{[29]}$ In Moon et al, ${ }^{[33]}$ study irregular shape was not associated with malignancy but there was higher percentage of hypoechoechogenicity in malignant nodes. Some studies were in favor of sonography markers for differentiating malignant and benign cases, however none of them can prove the malignancy decisively.

This present study showed that the smallness of nodule cannot eliminate the chance of malignancy and it is required for all nodules of any size to be investigated further. As mentioned in other studies, there is no difference regarding malignancy between nodulessmaller or larger than 10 mm. ${ }^{[34]}$ Cappelli et al, ${ }^{[35]}$ study showed that considering thyroid tumors of larger than $10 \mathrm{~mm}$ resulted in not detecting $19 \%$ of malignancies. Other studies have also questioned using exact sizes for suspecting malignant nodules. ${ }^{[19,24]}$ In a study it is recommended to do FNA even for $5 \mathrm{~mm}$ nodules.28 In another study, nodes larger than $10 \mathrm{~mm}$ did not increase the chance of malignancy. ${ }^{[23]}$ Therefore, it seems that the thyroid nodule size is not a good indicator for future actions, such as FNA or surgery, and malignancy must be suspected in nodules of any size. Our study also had limitations. One of its limitations was the small sample size; therefore it was not possible to use logistic regression analysis. It is recommended to conduct a similar study with larger sample size in order to identify the malignancy markers more accurately. Finally, since a single investigator interpreted the US findings, interobserver variability in the interpretation of the sponge-like appearance and US characteristics was not evaluated.

\section{Conclusion}

In conclusion, Based on the result of this study, thyroid nodule size must not be considered as a criterion for malignancy and thyroid nodules of any size must be suspected as malignant. Important criteria for malignancy include irregular edges, being Solid hypoechogenicity and being a single nodule respectively. However, the presence of calcifications in the nodule by US indicates a higher risk of malignancy and should prompt the clinician to evaluate the nodule further with repeat FNA.

\section{References}

1. Wolinski K, Szkudlarek M, Szczepanek-Parulska E, Ruchala M. Usefulness of different ultrasound features of malignancy in predicting the type of thyroid lesions: a meta-analysis of prospective studies. Pol Arch Med Wewn 2014;124:97-104.

2. Welker MJ, Orlov D. Thyroid nodules. Am Fam Physician 2003;67(3):559-566.

3. Cooper DS. Revised American Thyroid Association management guidelines for patients with thyroid nodules and differentiated thyroid cancer. Thyroid 2009;19(11):1167- 1214.

4. Mazzaferri EL. Management of a solitary thyroid nodule. N Engl J Med 1993;328(8):553-559.

5. Wiest PW, Hartshorne MF, Inskip PD, et al. Thyroid palpation versus high-resolution thyroid ultrasonography in the detection of nodules. J Ultrasound Med 1998;17(8):487-496.

6. Cronan JJ. Thyroid nodules: is it time to turn off the US machines? Radiology 2008;247(3):602-604. 
7. Mortensen JD, Woolner LB, Bennett WA. Gross and microscopic findings in clinically normal thyroid glands. J ClinEndocrinolMetab 1955;15(10):1270-1280.

8. Frates MC, Benson CB, Doubilet PM, Kun ᄀreuther E, Contreras M, Cibas ES, Orcutt J, Moore FJ, Larsen PR, Marqusee E and

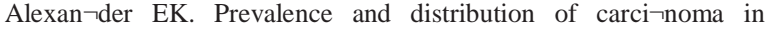
patients with solitary and multiple thyroid nodules on sonography. J ClinEndocri $\neg$ nolMetab 2006; 91: 3411-3417.

9. Siegel R, Ma J, Zou Z and Jemal A. Cancer sta-tistics, 2014. CA Cancer J Clin 2014; 64: 9-29.

10. Maia FF, Matos PS, Silva BP, Pallone AT, Pavin EJ, Vassallo J and Zantut-Wittmann DE. Role of ultrasound, clinical and scintigraphycparame $\neg$ ters to predict malignancy in thyroid nodule. Head Neck Oncol 2011; 3: 17.

11. Cakir B, Aydin C, Korukluoglu B, Ozdemir D, Sisman IC, Tuzun D, Oguz A, Guler G, Guney G, Kusdemir A, Sanisoglu SY and Ersoy R. Diag $\neg$ nostic value of elastosonographicallydeter $\neg$ mined strain index in the differential diagnosis of benign and malignant thyroid nodules. Enᄀdocrine 2011; 39: 89-98.

12. Iannuccilli JD, Cronan JJ and Monchik JM. Risk for malignancy of thyroid nodules as assessed by sonographic criteria: the need for biopsy. J Ultrasound Med 2004; 23: 1455-1464.

13. Lew JI, Rodgers SE, Solorzano CC. Developments in the use of ultrasound for thyroid câncer. Current Opinion in Oncology 2010;22(1):11-16.

14. Baskin HJ. Ultrasound of thyroid nodules. In: Baskin HJ, editor. Thyroid ultrasound and ultrasound-guided FNA biopsy. Boston: Kluwer Academic Publisher 2007;P-71-86.

15. Moon WJ, Jung SL, Lee JH, et al. Benign and malignant thyroid nodules: US differentiation-retrospective multicenter study. Radiology 2008;247(3):762-770.

16. Tabaqchali MA, Hanson JM, Johnson SJ, Wadehra V, Lennard TW, Proud G. Thyroid aspiration cytology in Newcastel: s sox year cytology/histology correlation study. Ann R CollSurgEngl 2000;82(3):149-55.

17. Safirullah, Mumtaz N, Khan A. Role of Fine Needle Aspiration Cytology (FNAC) in the diagnosis of thyroid. J Postgrad Med Inst 2004;18(2):196-201.

18. Ramsden J, Watkinson JC. Thyroid cancers. Scott-Brown's Otorhinolaryngology, Head and Neck Sugery. 7th edition, vol 2, Hodder Arnold, 2008:2663-701.

19. Iannuccilli JD, Cronan JJ, Monchik JM. Risk for malignancy of thyroid nodules as assessed by sonographic criteria: the need for biopsy. J Ultrasound Med. 2004;23(11):1455-1464.

20. Cappelli C, Castellano M, Pirola I, Gandossi E, De Martino E, Cumetti D, et al. Thyroid nodule shape suggests malignancy. Eur J Endocrinol. 2006;155(1):27-31

21. Lin JD, Chao TC, Huang BY, Chen ST, Chang HY, Hsueh C.
Thyroid cancer in the thyroid nodules evaluated by ultrasonography and fine-needle aspiration cytology. Thyroid. 2005;15(7):708-717.

22. Lee YH, Kim DW, In HS, Park JS, Kim SH, Eom JW, et al. Differentiation between benign and malignant solid thyroid nodules using an US classification system. Korean J Radiol. 2011;12(5):559567.

23. Ugurlu S, Caglar E, Yesim TE, Tanrikulu E, Can G, Kadioglu P. Evaluation of thyroid nodules in Turkish population. Intern Med. 2008;47(4):205-209.

24. Baier ND, Hahn PF, Gervais DA, Samir A, Halpern EF, Mueller PR, et al. Fine-needle aspiration biopsy of thyroid nodules: experience in a cohort of 944 patients. AJR Am J Roentgenol. 2009;193(4):11751179.

25. Mazeh H, Beglaibter N, Prus D, Ariel I, Freund HR. Cytohistologic correlation of thyroid nodules. Am J Surg. 2007;194(2):161-163.

26. Kim DW, Lee EJ, Kim SH, Kim TH, Lee $\mathrm{SH}$, Kim DH, et al. Ultrasound-guided fine-needle aspiration biopsy of thyroid nodules: comparison in efficacy according to nodule size. Thyroid. 2009; 19(1):27-31.

27. Koike E, Noguchi S, Yamashita H, Murakami T, Ohshima A, Kawamoto H. Ultrasonographic characteristics of thyroid nodules: prediction of malignancy. Arch Surg. 2001;136(3):334-337.

28. Kovacevic DO, Skurla MS. Sonographic diagnosis of thyroid nodules: correlation with the results of sonographically guided fineneedle aspiration biopsy. J Clin Ultrasound. 2007;35(2):63-67.

29. Kim EK, Park CS, Chung WY, Oh KK, Kim DI, Lee JT, et al. New sonographic criteria for recommending fine-needle aspiration biopsy of nonpalpable solid nodules of the thyroid. AJR Am J Roentgenol. 2002;178(3):687-691.

30. Taneri F, Kurukahvecioglu O, Ege B, Yilmaz U, Tekin E, Cifter C, et al. Prospective analysis of 518 cases with thyroidectomy in Turkey. EndocrRegul. 2005;39(3):85-90.

31. Popowicz B, Klencki M, Lewinski A, Slowinska-Klencka D. The usefulness of sonographic features in selection of thyroid nodules for biopsy in relation to the nodule's size. Eur $\mathrm{J}$ Endocrinol. 2009;161(1):103-111.

32. Algin O, Algin E, Gokalp G, Ocakoglu G, Erdogan C, Saraydaroglu $\mathrm{O}$, et al. Role of duplex power Doppler ultrasound in differentiation between malignant and benign thyroid nodules. Korean J Radiol. 2010;11(6):594-602.

33. Moon WJ, Jung SL, Lee JH, Na DG, Baek JH, Lee YH, et al. Benign and malignant thyroid nodules: US differentiation-- multicenter retrospective study. Radiology. 2008;247(3):762-770.

34. Papini E, Guglielmi R, Bianchini A, Crescenzi A, Taccogna S, Nardi $\mathrm{F}$, et al. Risk of malignancy in nonpalpable thyroid nodules: predictive value of ultrasound and color-Doppler features. J ClinEndocrinolMetab. 2002;87(5):1941-1946.

Copyright: ( $\odot$ the author(s), publisher. Asian Journal of Medical Radiological Research is an Official Publication of "Society for Health Care \& Research Development". It is an open-access article distributed under the terms of the Creative Commons Attribution Non-Commercial License, which permits unrestricted non-commercial use, distribution, and reproduction in any medium, provided the original work is properly cited.

How to cite this article: Neelapu KK. Evaluation on Thyroid Nodule Malignancy by Ultrasound Findings: A Teaching Hospital Based Study. Asian J. Med. Radiol. Res. 2018;6(1):1-4.

DOI: dx.doi.org/10.21276/ajmrr.2018.6.1.1

Source of Support: Nil, Conflict of Interest: None declared 